\title{
Immediate Effects of a Single Spinal Manipulation on Lower-Limb Strength in Healthy Individuals: A Critically Appraised Topic
}

\author{
Christopher Kevin Wong, Lizbeth Conway, Grant Fleming, Caitlin Gopie, \\ Dara Liebeskind, and Stephen Xue
}

\begin{abstract}
Clinical Scenario: Many people with lower quarter musculoskeletal dysfunction present with muscle weakness. Strength training hypertrophies muscle and increases strength, but often requires periods over 6 weeks, which can exceed the episode of care. Weakness can persist despite muscle hypertrophy, particularly in the early stages of joint pathology or in the presence of limb or spinal joint hypomobility, which may inhibit muscle activation. Emerging evidence suggests spinal manipulation can increase short-term strength. Screening for specific muscle weakness that could benefit from manipulation to particular spinal segments could facilitate efficient clinical intervention. Although the neuromuscular mechanisms through which manipulation can increase strength remains a topic of investigation, immediate gains can benefit patients by jump-starting an exercise program to train new muscle function gained and enhancing the motivation to continue strengthening. Evidence from randomized controlled trials would provide support for using manipulation to increase muscle strength, while studying healthy people would eliminate confounding factors, such as pain and pathology. Clinical Question: Does randomized controlled trial-level evidence support the concept that a single lumbar spine manipulation session can increase lower-limb strength in healthy individuals? Summary of Key Findings: Level $1 \mathrm{~b}$ evidence of moderate quality from 3 randomized controlled trials showed immediate small to large effect size muscle strength increases immediately after lumbar spine manipulation. Clinical Bottom Line: Lumbar spine manipulation can result in immediate lower-limb isometric strength increases. While healthy people with normal muscle strength may improve minimally, joint manipulation for people with knee and hip weakness who are otherwise healthy can result in large effect size strength gains. Strength of Recommendation: Moderate quality level $1 \mathrm{~b}$ evidence from randomized controlled trials with small samples support the use of spinal manipulation to immediately increase lower-limb strength. Additional studies investigating impact on strength and function immediately in people with musculoskeletal pathology are warranted.
\end{abstract}

Keywords: musculoskeletal manipulation, manual therapy, muscle, hip

\section{Clinical Scenario}

People with musculoskeletal lower quarter dysfunction, whether knee pain, hip arthritis, or low-back pain, can present with lowerlimb muscle weakness. Exercise to strengthen weakened muscles is a rehabilitation staple: early strength gains observed in the first 2 weeks have been attributed to neural adaptations that facilitate muscle activation, ${ }^{1}$ while muscle hypertrophy and strength gains occur later, after 6 to 13 weeks. ${ }^{2}$ Recent research has shown that, despite muscle hypertrophy, weakness can persist, particularly in the early stages of joint pathology. 3,4

Joint and ligamentous hypomobility may inhibit the activation of surrounding muscles or muscle synergists. ${ }^{5,6}$ Hypomobile spinal joints may also inhibit muscle function within the specific myotome. ${ }^{7}$ An early randomized controlled trial found quadriceps strength was significantly increased after manipulation to the L3-L4 lumbar segments. ${ }^{8}$ Increased neuromuscular excitability and maximal voluntary contraction force of the gastrocsoleus muscle have also been observed after a single spinal thrust manipulation, derived from an 11-subject study that utilized a crossover design that can obscure treatment outcomes due to potential carryover effects. ${ }^{9}$ Both studies

Wong is with the Department of Rehabilitation and Regenerative Medicine, Columbia University Irving Medical Center, New York, NY, USA. Conway, Fleming, Gopie, Liebeskind, and Xue are with the Program in Physical Therapy, Columbia University, New York, NY, USA. Wong (ckw7@ cumc.columbia.edu) is corresponding author. excluded people with diagnosed pathology, which limits clinical applicability, but also eliminates the many confounding factors that come with pathology, such as pain, fear-avoidance behaviors, and pathology-related musculoskeletal structural dysfunction.

With the growing emphasis on patient-centered care to produce efficient and cost-effective health care outcomes, achieving the fastest gains possible has become a priority for today's clinician. From the limited evidence that suggests spinal manipulation impacts lower-limb strength emerges the question of whether recent evidence from randomized controlled trials demonstrates increased lower-limb strength after spinal manipulation.

\section{Clinical Question}

Does randomized controlled trial-level evidence support the concept that a single session of lumbar spine manipulation can increase lower quarter strength in healthy individuals?

\section{Summary of Search, Best Evidence Appraised, and Key Findings}

- Three randomized controlled trials were included.,

- Manipulations included high-velocity, low-amplitude thrust ${ }^{7,10}$; and grade 3 nonthrust manipulation. ${ }^{11}$

- Two studies were screened for strength impairments before manipulation treatment. ${ }^{7,11}$ 
- All studies showed immediate small to large effect size isometric muscle strength increases, with knee extension and flexion, and hip flexion, extension, and abduction documented.

- Moderate GRADE evidence from level $1 \mathrm{~b}$ evidence demonstrated that spinal manipulation resulted in immediate musclestrength increase.

\section{Clinical Bottom Line}

Lumbar spine manipulation resulted in immediate lower-limb isometric strength increases. Although the specific neuromuscular mechanism through which strength increased remains a topic of investigation, ${ }^{1}$ immediate strength gains can benefit patients by jump-starting an exercise program and providing motivation to adhere to comprehensive physical therapy. While healthy patients with normal range of motion and muscle strength may see minimal small effect size strength improvements, ${ }^{10}$ a single-joint manipulation for healthy asymptomatic people who present with limited joint mobility and knee and hip weakness may expect immediate larger effect size increases in strength. ${ }^{11}$ Thus, screening for weakness associated with a local joint or spinal segment and applying a spinal manipulation to the relevant segment ${ }^{7}$ followed by exercises to train any newly gained muscle function may be a clinically efficient approach to developing strength.

\section{Strength of Recommendation}

The level $1 \mathrm{~b}$ evidence from randomized controlled trials supports the use of spinal manipulation to immediately increase lower-limb strength, though the findings were limited by the small total number of subjects included $(\mathrm{N}=115)$. The quality of the combined body of evidence was downgraded using the Cochrane GRADE system from high to moderate due to inconsistent blinding ${ }^{7,10}$ and potential selection bias. ${ }^{11}$

\section{Search Strategy}

The search strategy was established a priori and performed using the Columbia University Irving Medical Center computer network from March to July in 2019.

\section{Terms Used to Guide Search Strategy}

P. Population: "healthy," "not surgical"

I. Intervention: "lumbar manipulation," "spinal manipulation," "spinal mobilization"

C. Comparison: "control," "no treatment," "sham," "placebo"

O. Outcome: "muscle strength," "isometric strength," "lowerlimb strength," "dynamometer"

\section{Sources of Evidence Searched}

- Cochrane Library

- OVID Medline (including PubMed)

- Allied and Complementary Medicine Database (AMED)

- Cumulative Index to Nursing and Allied Health Literature (CINAHL)
- Web of Science was used to search for articles that referenced any included articles.

\section{Inclusion and Exclusion Criteria}

Studies published in English within the past 10 years (2009-2019) that met the following criteria were selected for review.

\section{Inclusion criteria:}

P. Assessed healthy individuals without known pathology, with or without limb weakness.

I. Provided intervention including spinal manipulation/ mobilization of any grade

C. Utilized a control, sham, or placebo comparison group

O. Assessed lower-limb strength

\section{Exclusion criteria:}

P. Studies with subjects who were diagnosed with any pathology, postsurgical or nonhuman

I. Nondirect joint manipulation/mobilization

C. Studies with crossover designs or that lacked a comparison group

O. Studies limited to EMG evaluation, upper-limb strength

\section{Results of Search}

Three level $1 \mathrm{~b}$ randomized controlled trials (see Table 1) were identified that met the study criteria and were determined to be the best available evidence and thus selected for inclusion.

\section{Best Evidence}

The included studies were selected as best evidence because all 3 were randomized controlled trials categorized as level $1 \mathrm{~b}$ evidence, based on the 2011 levels of evidence from the Centre for EvidenceBased Medicine, which compared the effects of lumbar manipulation to a control condition of either range of motion or simulated manipulation. All 3 studies found an immediate statistically significant increase in either knee or hip strength measured as isometric force output or torque, with effect sizes ranging from small to large (see Table 2). The observed effect sizes were less than those observed in early work, which assessed only quadriceps strength in 30 chiropractic students and may have been vulnerable to selection bias. $^{8}$ In the more recent studies reviewed here, it is possible that selection bias could also arise through subject recruitment from interdisciplinary health discipline students. ${ }^{11}$ Other sources of bias include potential confirmation bias due to a lack of assessor blinding. ${ }^{10}$ The Cochrane GRADE system was used to assess study quality, with the quality of the combined body of evidence downgraded from high to moderate due to inconsistent blinding ${ }^{7,10}$ and potential selection bias. ${ }^{11}$ Overall, the best evidence resulting from this search strategy yielded moderate-quality level $1 \mathrm{~b}$ evidence from small randomized controlled trials that supports the use of a single lumbar spine manipulation to immediately increase lower-limb strength in healthy individuals. 
Table 1 Summary of Study Designs of Included Articles

\begin{tabular}{lclcc}
\hline GRADE & Level of evidence & Study design & Number of included articles & Author \\
\hline Moderate & $1 \mathrm{~b}$ & Randomized controlled trials & 3 & Chilibeck et al $^{7}$ \\
& & & Grindstaff et al $^{10}$ \\
& & & Yuen et al $^{11}$ \\
\hline
\end{tabular}

Table 2 Characteristics of Included Studies

\begin{tabular}{|c|c|c|c|}
\hline & Grindstaff et al ${ }^{10}$ & Chilibeck et $\mathrm{al}^{7}$ & Yuen et al ${ }^{11}$ \\
\hline Participants & $\begin{array}{l}42 \text { healthy asymptomatic people, aged } \\
21-36 \text { y }\end{array}$ & $\begin{array}{l}49 \text { healthy people, mean age } 54 \mathrm{y} \text { with } \\
\geq 15 \% \text { leg strength difference }\end{array}$ & $\begin{array}{l}24 \text { interdisciplinary health students, aged } \\
18-29 \text { y with hip-flexor weakness }\end{array}$ \\
\hline Study design & $\begin{array}{l}\text { Randomized controlled trials, blinding not } \\
\text { noted }\end{array}$ & $\begin{array}{l}\text { Randomized controlled trials, blinded } \\
\text { assessor, and subjects }\end{array}$ & $\begin{array}{l}\text { Randomized controlled trials, blinded } \\
\text { assessor and subjects }\end{array}$ \\
\hline Intervention & $\begin{array}{l}\text { High-grade lumbopelvic joint thrust } \\
\text { manipulation }\end{array}$ & $\begin{array}{l}\text { High-velocity, low-amplitude thrust at end } \\
\text { range of motion, targeting specific nerve } \\
\text { roots }\end{array}$ & $\begin{array}{l}\text { Grade III spinal rotation manipulation } \\
\text { L2-L3 (80 oscillations/min) }\end{array}$ \\
\hline $\begin{array}{l}\text { Comparison } \\
\text { condition }\end{array}$ & 3-Min prone extension on elbows & $\begin{array}{l}\text { Simulated manipulation in end range of } \\
\text { motion }\end{array}$ & $\begin{array}{l}\text { Grade III hip-flexion manipulation } \\
\text { (80 oscillation/min) }\end{array}$ \\
\hline Methodology & $\begin{array}{l}\text { Manipulation performed. Isometric } \\
\text { strength and muscle activation tested } \\
\text { immediately, 20-, 40-, and 60-min } \\
\text { posttreatment. }\end{array}$ & $\begin{array}{l}\text { Subject strength screened for eligibility. } \\
\text { Manipulation performed. Isometric } \\
\text { strength measured pretreatment and } \\
\text { posttreatment. }\end{array}$ & $\begin{array}{l}\text { Subjects screened with break test for } \\
\text { eligibility. Manipulation performed. } \\
\text { Isometric strength measured pretreatment } \\
\text { and posttreatment. }\end{array}$ \\
\hline $\begin{array}{l}\text { Outcome } \\
\text { measures }\end{array}$ & $\begin{array}{l}\text { Knee-extension isometric (load cell) force } \\
\text { output }\left(85^{\circ} \text { hip flexion, } 90^{\circ} \text { knee flexion). }\right. \\
\text { Percentage quadriceps activation. }\end{array}$ & $\begin{array}{l}\text { Peak isometric (isokinetic dynamometer) } \\
\text { torque hip flexors, extensors, abductors, } \\
\text { and knee flexors. Absolute and relative } \\
\text { strength difference (in \%). }\end{array}$ & $\begin{array}{l}\text { Differences in isometric (handheld dyna- } \\
\text { mometer) hip-flexor torque, change in } \\
\text { torque, and functional hop distance. }\end{array}$ \\
\hline $\begin{array}{l}\text { Main } \\
\text { findings }\end{array}$ & $\begin{array}{l}\text { Significant increase in quad-force output } \\
(3.1 \%) \text { and activation }(4.7 \%) \text { in manipu- } \\
\text { lation group vs. passive range of motion } \\
\text { group }(P=.003, P=.04) \text { and prone } \\
\text { extension group }(P=.02, P=.01) \\
\text { immediately post joint manipulation. } \\
\text { Cohen } d=0.12\end{array}$ & $\begin{array}{l}\text { Reduced strength differences between } \\
\text { limbs }(P=.05) \text { from } 57 \% \text { to } 5 \% \text { for knee } \\
\text { flexion and from } 24 \% \text { to } 11 \% \text { for hip } \\
\text { flexion. } \\
\text { Spinal manipulation increased weak limb } \\
\text { strength during hip abduction }(P=.03) \text {. } \\
\text { Cohen } d=0.31-0.30 \text { (knee flexion); } \\
0.30-0.32 \text { (hip flexion); } 0.26-0.29 \\
\text { (hip abduction) }\end{array}$ & $\begin{array}{l}\text { Lumbar manipulation had a greater positive } \\
\text { percentage change in torque }(P=.02) . \\
\text { Cohen } d=-1.03\end{array}$ \\
\hline $\begin{array}{l}\text { Study } \\
\text { limitations }\end{array}$ & $\begin{array}{l}\text { No mention of blinding. Potential local } \\
\text { muscle fatigue after warm-up. Test leg } \\
\text { determined via coin toss. Long-term } \\
\text { strength not measured. }\end{array}$ & $\begin{array}{l}\text { Small sample size. Participants may not } \\
\text { have remained fully blinded. Authors cite } \\
\text { potential for type } 1 \text { statistical error. } \\
\text { Long-term strength not measured. }\end{array}$ & $\begin{array}{l}\text { Small sample of health discipline students } \\
\text { with narrow age range. Strength measured } \\
\text { at } 90^{\circ} \text { after manipulation. Break test used } \\
\text { for screening. No long-term follow-up. }\end{array}$ \\
\hline $\begin{array}{l}\text { Level of } \\
\text { evidence }\end{array}$ & $1 \mathrm{~b}$ & $1 b$ & $1 \mathrm{~b}$ \\
\hline Conclusion & $\begin{array}{l}\text { Immediately after lumbopelvic joint } \\
\text { manipulation, quadriceps force and muscle } \\
\text { activation increased significantly. }\end{array}$ & $\begin{array}{l}\text { Spinal manipulation improved hip strength } \\
\text { and reduced knee and hip-flexion muscle } \\
\text { imbalance. }\end{array}$ & $\begin{array}{l}\text { Grade } 3 \text { lumbar rotation mobilization sig- } \\
\text { nificantly improved hip-flexor strength, but } \\
\text { not hopping distance. }\end{array}$ \\
\hline
\end{tabular}

\section{Implications for Practice, Education, and Future Research}

This critically appraised topic included randomized controlled trials that investigated people without known pathology in order to explore the isolated question of whether a single spinal manipulation can produce immediate lower-limb strength gains. In people with known pathology, such as arthritis or lumbar radiculopathy, weakness may be attributed to a variety of sources, such as pain and fear-avoidance behaviors, limited range of motion or muscle atrophy, or neurologic patency, which can complicate the strength outcomes of any intervention. While the inclusion of healthy individuals minimizes the potential exposure to such complicating clinical factors, including healthy subjects does not preclude the existence of specific asymptomatic impairments, which can occur in healthy people as well as people in the early stages of joint pathology. 3,4

One limitation of randomized controlled trials is that all subjects receive the same treatment, regardless of individual needs as indicated by specific impairment. While the standardized protocol of a randomized controlled trial ensures consistency of care, the impact of an intervention on people who do not present with the relevant impairment would logically be less, and the observed effects on a group could be negatively biased. Two studies addressed this limitation by operationally matching the impairment to a specific intervention by screening for specific lower-limb weakness. ${ }^{7,11}$ The indicators for inclusion and manipulation were muscle weakness assessed by manual muscle "break tests" 11 and limb strength asymmetry $\geq 15 \%$ assessed using isometric dynamometer 
strength testing. ${ }^{7}$ Screening can facilitate clinical decision making; for instance, decreased quadriceps strength can indicate manipulation at the L3/L4 myotome segment. ${ }^{7}$ In the combined studies, knee extension and flexion, and hip extension, flexion, and abduction were all observed to have increased isometric strength after manipulation (Table 2). The negligible observed effect size changes in strength in one study may be explained by the lack of a screening method. ${ }^{10}$ Matching a specific impairment to a specific intervention is a logical step in treatment planning for patientcentered care. In clinical practice, screening for a variety of impairments may be useful in identifying the potential applicability for manipulation, including myotomal weakness, ${ }^{7}$ specific muscle weakness, ${ }^{11}$ or limited mobility in related fascia ${ }^{12}$ or joints. ${ }^{3-5}$

All studies tested healthy individuals without specific musculoskeletal pathology, but the type of spinal manipulation techniques used in the included studies varied: 2 used high-velocity, lowamplitude thrust ${ }^{7,10}$ and one used grade 3 manipulations. ${ }^{11}$ The grade or technique of the spinal manipulation used to ameliorate the identified strength impairment may not be critical for achieving the outcome of immediately increased strength. The largest effect sizes observed in the included studies occurred after both thrust ${ }^{7}$ and nonthrust manipulation. ${ }^{11}$ The large effect size change observed after nonthrust grade 3 manipulation ${ }^{11}$ was also comparable to the large effect size change in quadriceps strength seen after the L3-L4 lumbar spine high-velocity amplitude thrust in the earlier study. ${ }^{8}$ Matching the intervention to the specific impairment may be an important factor, though future research is needed to explore this approach. In addition, the impact of spinal manipulation on specific segments may differ when performed on people with symptomatic pain and dysfunction. The findings of the reviewed studies suggest that a study of the effects of spinal manipulation on muscle strength in people with diagnosed pathology such as hip arthritis or lowback pain would be warranted.

The included studies were not designed to determine the mechanism through which strength was increased. Given the passive manipulation intervention and immediacy of the outcome, muscle hypertrophy was not a possible explanation, as at least 6 weeks is typically required for hypertrophy-related strength gains. ${ }^{2}$ Recent research is suggestive of other musculoskeletal system explanations for the observed strength gain. Women with chronic hip-joint pain who demonstrated significantly less hip-abduction strength than age-matched controls despite having greater muscle hypertrophy measured with magnetic resonance imaging. ${ }^{3}$ For people with joint hypomobility or early joint pathology, muscle weakness may occur, despite apparent muscle hypertrophy, because limited mobility may cause the muscles to work less effectively due to joint hypomobility, pathology, or functional deficits. ${ }^{4}$ While the mechanical and neurologic processes by which the manipulation of hypomobile joints facilitate surrounding muscles to activate remain unresolved, immediate strength increases have been observed, particularly in the 2 identified in this search that included subjects prescreened for muscle weakness. 7,11

The longevity of the observed strength increases was not determined in any of the 3 included studies. Any observed strength increases related to potential musculoskeletal or neuromuscular factors contributing to the treatment effects may be short-lived, and future investigations exploring effects beyond the immediate posttreatment period remain an area for future study. In addition, further investigation into the impact of immediate isometric strength gain on functional activities after spinal manipulation is needed. Only one study assessed an activity level limitation, and the chosen function-hopping-is a multifactorial activity that would not necessarily change with an isolated increase in hipflexion strength. ${ }^{11}$

In clinical practice, a rapid initial strength gain may contribute to a patient's trust in spinal manipulation as a helpful intervention, sense of improvement within a plan of care, and rapport with the therapist. Spinal manipulation, when indicated to obtain an immediate strength improvement for specific limb weakness, could jump-start a strengthening program and enhance patient motivation for rehabilitation.

\section{Conclusion}

The use of lumbar spine manipulation to facilitate lower-limb isometric strength increases was supported by the best level $1 \mathrm{~b}$ moderate-quality evidence available. While the evidence was derived from small studies, without long-term follow-up, the immediate short-term gains and short duration of the technique suggests spinal manipulation can be an efficient and effective technique. Such rapid gains can provide a starting point for a strengthening program but may be best integrated with other therapeutic approaches for strengthening and functional improvement. Joint manipulation to enhance specific strength could be followed by exercise to optimize joint and muscle performance with successful neuromuscular movement patterns that can reduce activity limitations and lead to sufficient cardiovascular capacity to return to prior function in relevant environments.

\section{Acknowledgments}

The authors have no conflicts to declare. This project was unfunded.

\section{References}

1. Moritani T. Neuromuscular adaptations during the acquisition of muscle strength, power and motor tasks. J Biomech. 1993;26(suppl 1):95-107. doi:10.1016/0021-9290(93)90082-P

2. Schoenfeld BJ, Grgic J, Ogborn D, Krieger JW. Strength and hypertrophy adaptations between low- vs high-load resistance training: a systematic review and meta-analysis. J Strength Cond Res. 2017;31(12):3508-3523. PubMed ID: 28834797 doi:10.1519/JSC. 0000000000002200

3. Mastenbrook MJ, Commean PK, Hillen TJ, et al. Hip abductor muscle volume and strength differences between women with chronic hip joint pain and asymptomatic controls. J Orthop Sports Phys Ther. 2017;47(12):923-930. PubMed ID: 28992772 doi:10.2519/jospt. 2017.7380

4. Grimaldi A, Richardson C, Stanton W, Durbridge G, Donnelly W, Hides J. The association between degenerative hip joint pathology and size of the gluteus medius, gluteus minimus and piriformis muscles. Man Ther. 2009;14(6):605-610. PubMed ID: 19695944 doi:10.1016/j.math.2009.07.004

5. De Souza Campos C Jr, Bracht MA, dos Santos MJ. The effect of finger joint hypomobility on precision grip force. J Hand Ther. 2013; 26(4):323-329. doi:10.1016/j.jht.2013.05.007

6. Solomonow M. Ligaments: a source of musculoskeletal disorders. J Bodyw Mov Ther. 2009;13(2):136-154. PubMed ID: 19329050 doi:10.1016/j.jbmt.2008.02.001

7. Chilibeck PD, Cornish SM, Schulte A, et al. The effect of spinal manipulation on imbalances in leg strength. J Can Chiropr Assoc. 2011;55(3):183-192. PubMed ID: 21886280 
8. Pollard H, Ward G. Strength change of quadriceps femoris following a single manipulation of the L3/L4 vertebral motion segment: a preliminary investigation. J Neuromusc Sys. 1996;4(4):137-144.

9. Christiansen TL, Niazi IK, Holt K, et al. The effects of a single session of spinal manipulation on strength and cortical drive in athletes. Eur J Appl Physiol. 2018;118(4):737-749. PubMed ID: 29327170 doi:10. 1007/s00421-018-3799-x

10. Grindstaff TL, Hertel J, Beazell JR, Magrum EM, Ingersoll CD. Effects of lumbopelvic joint manipulation on quadriceps activation and strength in healthy individuals. Man Ther. 2009;14(4):415-420. PubMed ID: 18805726 doi:10.1016/j.math.2008.06.005

11. Yuen TS, Lam PY, Lau MY, et al. Changes in lower limb strength and function following lumbar spinal mobilization. J Manipulative Physiol Ther. 2017;40(8):587-596. doi:10.1016/j.jmpt.2017.07.003

12. Bolívar YA, Munuera PV, Padillo JP. Relationship between tightness of the posterior muscles of the lower limb and plantar fasciitis. Foot Ankle Int. 2013;34(1):42-48. doi:10.1177/1071100712459173 